\title{
$O$ poder do Terceiro Setor: \\ a teoria do agendamento às avessas
}

\section{Willian Silva Bonfim*}

\begin{abstract}
Resumo
Entender o papel dos News Promoters na construção social da notícia, com relevância às fontes como um dos fatores-chave na definição do Agenda Setting, a partir da relação de organismos do Terceiro Setor com o jornalismo impresso, é o objetivo central deste trabalho. À luz do conceito de enquadramento, utilizado por Erving Goffman, o autor analisou uma série especial de cinco reportagens sobre o tema Responsabilidade Social das Empresas, publicadas no jornal O Popular, maior jornal de circulação em Goiás, em dias alternados de abril a maio de 2002. A análise de conteúdo das reportagens sobre Cidadania Empresarial evidenciou o enquadramento a priori engendrado pelo Instituto Ethos e reproduzido por O Popular. $O$ estudo de caso concluiu que é preciso recolocar em xeque o poder do jornalismo, tão aclamado pela Teoria do Agendamento, retomando as questões colocados por Mawell E. MacCombs e Donald Shaw, pioneiros nos estudos de agendamento: "são os próprios media a estabelecer a agenda ou estes apenas refletem uma agenda estabelecida pelas suas fontes de informação?"

Palavras-chave: jornalismo, responsabilidade social, agenda Setting.
\end{abstract}

\section{O poder do jornalismo em questão}

Apesar da evolução e dos avanços na compreensão da Teoria do Agendamento, os estudos mais recentes apontam uma preponderância dos media na construção social da notícia e, portanto, na influência da Agenda Pública.

* Jornalista, professor da Universidade Estadual de Goiás e aluno do curso de mestrado em Comunicação da Universidade de Brasília.

Comun. Inf., v. 4, n. 1/2, p.73-92, jan./dez. 2001 


\section{4}

Os estudos mais atuais reafirmam o poder do jornalismo, mas identificam algumas questões ainda em aberto: 1) a incompleta compreensão da complexa dinâmica existente entre as fontes e os jornalistas, e, por conseguinte, da teia emaranhada que envolve a relação de forças e a interação, crucial entre (sobretudo) agentes especializados, em torno do bem conhecido como informação; 3) a inexistência de uma clara conceitualização e identificação dos fatores que intervêm nas influências mútuas entre as diversas agendas.

A ênfase recai ainda, muito fortemente, no papel dos jornalistas gatekeepers e/ou news assemblers - como principais atores no processo de construção da notícia - seleção e enquadramento - e, por conseguinte, na influência e definição da Agenda Pública.

Mesmo reconhecendo que editores e difusores desempenham um papel importante na modelação das percepções da realidade, autores como Mawell E. McCombs e Donald Shaw, pioneiros nos estudos de agendamento, afirmam que é necessário inquirir se são os próprios media a estabelecer a agenda ou se estes apenas refletem uma agenda estabelecida pelas suas fontes de informação.

Estudos iniciados na década de 80, que os autores definem como a quarta fase da pesquisa do Agendamento, inverteram o foco da pesquisa sobre a luta simbólica da construção da notícia para os atores que estão na outra ponta do agendamento: as fontes.

Conforme os autores, em artigo que analisa a "Evolução da Pesquisa Sobre o Agendamento: Vinte e cinco anos no mercado de Idéias"1 , enquanto as fases iniciais da pesquisa sobre o agendamento se concentravam na questão "Quem determina a agenda pública-e em que condições?", a mais recente fase de trabalho centrou a sua atenção na pergunta "Quem determina a agenda dos media?".

O papel dos promotores na construção da notícia fez Nelson Traquina apontar a existência de um problema a ser investigado: "Responder à questão de saber quais são os recursos determinantes que os promotores devem possuir na sua interação com os jornalistas para impor os seus acontecimentos e problemáticas na agenda (dos jornalistas e, por conseqüência, na agenda pública) e fazer passar seus frames na luta simbólica em torno do processo de significação". Clóvis de Barros Filho também afirma, em seu livro Ética na Comunicação, que "o papel das fontes relativiza sobremaneira a prerrogativa dos meios na construção da realidade social".

Comun. Inf., v. 4, n. 1/2, p.73-92, jan./dez. 2001 
Este estudo de caso situa-se na linha de estudos que procura entender o papel dos News Promoters na construção social da notícia, com relevância às fontes como um dos fatores-chave na definição do Agenda Setting, sobretudo para corroborar a hipótese de que está se solidificando no jornalismo impresso contemporâneo brasileiro uma tendência à prestação de serviço público, mais preocupado com as questões levantadas por Organizações Não-governamentais e na apresentação de suas temáticas e respostas de seus problemas.

Essa tendência, apontam alguns indícios, está sendo forjada pelo atual contexto, no qual o Terceiro Setor (ONGs) tem tido uma atuação determinante na definição de pautas e abordagens de assuntos sociais, somadas a outras iniciativas, como o Ano Internacional do Voluntariado, e à disseminação, junto ao empresariado, inclusive as empresas de comunicação, do conceito de "responsabilidade social".

Este estudo de caso pretende lançar algumas luzes quanto à articulação e organização do trabalho que têm desenvolvido entidades do Terceiro Setor - no caso, o Instituto Ethos de Empresas Responsabilidade Social - para fazer suas pautas, inclusive seus enfoques, ocuparem espaços na mídia impressa, no caso, o jornal O Popular, diário de maior circulação no Estado de Goiás, pertencente às Organizações Jaime Câmara, quarto maior grupo de comunicação do país.

\section{Novos atores na luta simbólica}

Num cenário onde o Estado moderno vem diminuindo progressivamente os investimentos em políticas públicas e a atuação no combate aos problemas sociais, emergiu nas últimas décadas no mundo e no Brasil novos atores sociais, que se caracterizam como Organizações Não-Governamentais (ONGs) e/ou Organizações da Sociedade Civil de Interesse Público (Ocips) e se articulam no que vem se convencionando chamar de Terceiro Setor.

Este último tem sido definido ${ }^{2}$ como "conjunto de iniciativas particulares sem fins lucrativos com um sentido público, composto por formas tradicionais de ajuda mútua (atividades assistenciais e beneficentes), movimentos sociais e associações civis (associações de bairro, grupos feministas), filantropia empresarial (fundações ligadas a empresas privadas) e ONGs".

Uma pesquisa-amostra com 196 ONGs filiadas à Associação Brasileira das Organizações Não-Governamentais (Abong), realizada de

Comun. Inf., v. 4, n. 1/2, p.73-92, jan./dez. 2001 
agosto a novembro de 2001 , demonstra que $52,04 \%$ atuam na área da educação; $38,27 \%$, na organização e participação popular; $36,73 \%$, na promoção dos direitos e acesso à justiça; $26,02 \%$, no fortalecimento de outras ONGs e movimentos populares; $25 \%$, em questões relacionadas a relações de gênero e discriminação sexual; $24,49 \%$, na área da saúde e $18,88 \%$, na área de meio ambiente.

Ajuda-nos a situar essa fase, as observações da professora Jacqueline OliveiraSilva ${ }^{3}$ :

"O acelerado crescimento da presença das Organizações Não Estatais na sociedade e a crise do Welfare State, faz com que reconheça-se teórica e empiricamente a existência de um Terceiro Setor na dinâmica social, operando em níveis diferenciados da vida social, a partir de processos de inclusão".

Mesmo os países mais subdesenvolvidos, afirma o professor Luiz Martins da Silva ${ }^{4}$, no artigo "Imprensa, Discurso e Interatividade" 5 , têm experimentado a emergência quase explosiva da chamada terceira via, nem pública (no sentido estatal) nem privada (no sentido mercadológico), que é representada pela atuação dos movimentos sociais, muitos deles cristalizados sob a forma de organizações nãogovernamentais (ONGs).

No Brasil, segundo estimativas de pesquisa da antropóloga Leilah Landim, professora da Universidade Federal do Rio de Janeiro (UFRJ), calcula-se que o Terceiro Setor, que engloba instituições da sociedade civil, conta com 230 mil ONGs e empregue 1,5 milhão de pessoas. Dessas, 249 ONGs são associadas à Abong.

A professora Lúcia Avelar ${ }^{6}$, em seu artigo "Elites Políticas, eleitorado brasileiro e perspectivas da democracia na década vindoura", analisando o atual processo por que passa a democracia brasileira e a atuação dos atores sociais neste contexto, reconhece que algumas ONGs são realmente eficazes, articulam-se de modo dinâmico, descentralizado e flexível entre os recursos do Estado e a sociedade. A professora acrescenta ainda:

\footnotetext{
"Mas, sem sombra de dúvida elas [as ONGs] são um exemplo da reconstituição de novas formas de instituições políticas que tentam estabelecer a relação entre as identidades particulares e o mundo de fluxos de poder, com o fortalecimento da sociedade".
}

Comun. Inf., v. 4, n. 1/2, p.73-92, jan./dez. 2001 
A evolução do número de ONGs reconhecidas pela Organização das Nações Unidas (ONU), de 1945 a 2002, demonstra bem o vigor e a ascensão do Terceiro Setor no planeta. As ONGs que se enquadram na primeira categoria - alcance global com grande número de membros e operando em questões variadas - cresceram de nove, em 1950, para 121 em 2000. As ONGs que têm o perfil da segunda categoria - regionais ou focadas em questões específicas - experimentaram um crescimento de 87, em 1950, para 1.204, em 2000. Já as organizações que se enquadram na terceira categoria - pequeno porte ou altamente especializadas, que trabalham diretamente com agências da ONU - registraram o maior salto: de 197, em 1945, para 3.089 , no último ano do milênio.

Este estudo de caso parte da perspectiva dada pelas teorias organizacional e construcionista que ajuda a entender a notícia, produto final da prática jornalística, como resultado de processos de interação social e de negociações. Pode-se afirmar, portanto, que o jornalismo é um produto socialmente construído a partir de determinados contextos, aberto às pressões dos promotores na produção da informação $\mathrm{e}$ se configura como um espaço social onde atuam interesses antagônicos, públicos e privados, na definição de sua identidade e modelo.

Adelmo Genro Filho ajuda-nos a perceber que "há uma hierarquia de contradições na sociedade, mas [que] os processos se conjugam e alternam sua principalidade definindo novas conjunturas. (...) Ora, se o todo se desenvolve e se cria, sendo por isso uma totalidade dialética, isso envolve contradições internas que são as verdadeiras fontes do desenvolvimento e contradições".

\section{A bandeira da responsabilidade social}

O Instituto Ethos de Empresas e Responsabilidade Social expressa bem esta nova realidade configurada pelas ONGs. Fundado em julho de 1998, a partir da iniciativa de um grupo de empresários que acreditam que o papel social da empresa vá além de sua participação no processo de desenvolvimento econômico e tecnológico, na geração de empregos e no pagamento de impostos, o Instituto Ethos reúne centenas de empresas associadas, cujo faturamento somado é de aproximadamente R $\$ 250$ bilhões - $25 \%$ do PIB brasileiro, segundo a organização - que empregam, aproximadamente, um milhão de pessoas.

Comun. Inf., v. 4, n. 1/2, p.73-92, jan./dez. 2001 
Essa ONG tem a missão de "mobilizar, sensibilizar e ajudar as empresas a compreender e incorporar o conceito de responsabilidade social no cotidiano de sua gestão, estabelecendo padrões éticos de relacionamento com os seus diversos públicos: funcionários, acionistas, fornecedores, consumidores, poder público, comunidade e meio ambiente".

O Instituto Ethos acredita que as empresas, ao adicionarem às suas competências básicas um comportamento ético e socialmente responsável, adquirem o respeito das pessoas e das comunidades beneficiadas por suas atividades e são gratificadas com o reconhecimento e o engajamento dos seus colaboradores e a preferência dos consumidores. Em última instância, portanto, a responsabilidade social é apresentada como um fator de sucesso empresarial.

O conceito de Responsabilidade Social formulado pelo Instituto Ethos, com base em experiências internacionais, se estrutura em uma série de indicadores:

1) Tratamento justo e transparente aos trabalhadores, fornecedores e consumidores: na escolha de parceiros - fornecedores e prestadores de serviços - que compartilham com a empresa a preocupação de dar um tratamento justo aos atores que se situam nos vários níveis - da produção ao consumo.

2) Clareza de onde os produtos são manufaturados: na identificação da rede de suprimento. Clareza de quem são os fornecedores, quais as fábricas utilizadas para a manufatura dos produtos, onde estão localizadas e suas capacidades de produção.

3) Destaque para itens relevantes sobre os Direitos Humanos: muitos dos direitos humanos, estabelecidos pela Declaração Universal dos Direitos Humanos, podem ser relevantes para a área empresarial. Como os relativos a: trabalho infantil, trabalho forçado, liberdade de associação, preconceitos discriminatórios, saúde e segurança.

4) Adoção de um código de conduta: criação de códigos que incorporem as leis trabalhistas locais e padrões internacionais aceitáveis de conduta e definem um guia para a empresa aferir até que ponto os itens relacionados estão sendo cumpridos de forma justa.

5) Nova relação com o meio ambiente: implementação de um novo padrão de relacionamento com os bens naturais renováveis e

Comun. Inf., v. 4, n. 1/2, p.73-92, jan./dez. 2001 
não-renováveis na perspectiva do desenvolvimento sustentável, tendo em vista o cuidado e a preservação.

Desde a sua origem, o Instituto Ethos manifesta abertamente a importância que dá à mídia em geral, e ao jornalismo em particular, como parceiros imprescindíveis na disseminação do conceito de Responsabilidade Social junto aos empresários, admitindo, inclusive, que sem eles a sua missão "não poderia ser levada a cabo".

Por isso, se organizou a partir da filosofia da criação de redes, por meio de parcerias e alianças estratégicas para a difusão, conceituação e conscientização do tema, envolvendo empresários, estudantes, pesquisadores, professores, jornalistas e ONGs. Assim como os professores são mobilizados numa rede própria, os jornalistas também são mobilizados na Rede Ethos de Jornalistas, que se situa, no organograma da entidade, dentro da linha mobilização para a sociedade em geral.

A necessidade de estabelecer um diálogo com a mídia e com o jornalismo levou o Ethos à articulação dessa rede, cujo papel é definir estratégias para a disseminação dessa nova cultura empresarial. Uma outra estratégia usada pelo grupo foi o lançamento do Prêmio Ethos de Jornalismo, em 28 de novembro de 2000, em São Paulo(SP), com o objetivo de reconhecer as melhores reportagens em mídia impressa e eletrônica sobre responsabilidade social empresarial, veiculadas em qualquer parte do país.

Iniciativa que conta com o apoio expresso, entre outras grupos, da Federação Nacional dos Jornalistas (FENAJ) e da Associação Brasileira de Imprensa (ABI), o Prêmio Ethos de Jornalismo condecora as reportagens que tenham contribuído para estimular as empresas a investirem em práticas socialmente responsáveis, como valores e transparência, público interno, preservação do meio ambiente e do patrimônio cultural, promoção dos direitos humanos e das relações com funcionários, fornecedores, consumidores, comunidade, governo e sociedade.

\section{Valores notícias do Terceiro Setor}

Pontualmente, têm aparecido na mídia e nos jornais impressos, de âmbito nacional e regionais, matérias estruturadas a partir do conceito de Responsabilidade Social, o que aponta para uma eficácia das estratégias do Instituto Ethos. Contudo, para além dos expedientes usados para disseminar as suas idéias e princípios e, por sua vez, determi-

Comun. Inf., v. 4, n. 1/2, p.73-92, jan./dez. 2001 


\section{0}

nar parte da Agenda Pública, resta saber onde reside o valor notícia das informações que veicula e quais são os critérios de noticiabilidade que condensa.

Em seu balanço sobre a teoria do Agendamento, Nelson Traquina aponta duas variáveis, entre outras, que parecem ser determinantes na constituição da agenda jornalística: 1) toda a atuação dos membros da tribo jornalística e, em particular, os critérios de noticiabilidade - a notoriedade, o conflito, a proximidade geográfica - que utilizam na seleção das ocorrências; 2) a ação estratégica dos promotores de notícias e os recursos que possuem e que são capazes de mobilizar para obterem acesso ao campo jornalístico.

É importante observar a clareza que o Instituto Ethos possui quanto à necessidade da "concorrência hábil entre promotores na mobilização de ocorrências como uma dimensão fulcral da luta simbólica para definir a Agenda Pública".

Exceto as estratégias do Greenpeace, ONG fundada em 1971, que atua em questões relacionados ao meio ambiente, os fatos produzidos pelo Terceiro Setor em geral, e pelo Instituto Ethos em particular, não podem ser enquadrados dentro do conceito de "acontecimento", tal qual foi formulado por Adriano Duarte Rodrigues ${ }^{7}$. Para este autor, o acontecimento é:

"Tudo aquilo que irrompe na superfície lisa da história entre uma multiplicidade aleatória de fatos virtuais. (...) Se situa, portanto, na escala de probabilidades de ocorrência, sendo tanto mais imprevisível quanto menos provável for a sua realização".

Uma das características das organizações que compõem o Terceiro Setor é possuir um saber especializado a respeito de suas áreas de atuação (infância e adolescência, educação, questões de gênero e etnia, geração de emprego e renda, direitos humanos, conflitos no campo, meio ambiente, habitação, etc). A informação veiculada pelo Terceiro Setor não possui o caráter aleatório nem imprevisível, mas, ao contrário, fundamenta-se no caráter eminentemente estratégico, no sentido de conquistar adeptos para suas causas e bandeiras. Estruturam-se a partir de características e valores previamente planejados, com vistas ao alcance de determinadas metas.

Adriano afirma ainda que "o acontecimento jornalístico irrompe sem nexo aparente nem causa conhecida e é, por isso, notável, digno

Comun. Inf., v. 4, n. 1/2, p.73-92, jan./dez. 2001 
de ser registrado na memória. Pertence ao mundo do acidente que deixa vestígios e altera a substância do mundo das coisas, das pessoas, das instituições". Três características, segundo o autor, possuem os acontecimentos que atingem a agenda dos medias noticiosos e são dignos de ser registrados na memória: o excesso, a falha e a inversão.

A informação produzida pelo Terceiro Setor situa-se dentro do que os autores Harvey Molotch e Marilyn Lester classificam como "acontecimentos de rotina" ou happennings, que se baseiam em "realizações intencionais" dos promotores. Ou seja, o acontecimento forma-se mediante de uma atividade humana intencional. Para esses autores, os acontecimentos podem ser classificados em intencionais e involuntários, nesta última categoria se inserem os acidentes e escândalos imprevisíveis.

Segundo Molotch e Lester, aqueles que não têm acesso regular ao campo jornalístico precisam de 'fazer notícia', entrando em conflito, de qualquer modo, com o sistema de produção jornalística, gerando a surpresa, o choque ou uma qualquer forma latente de agitação.

\section{Valores notícias dos jornais}

Até que ponto o Terceiro Setor e os jornais impressos compartilham os mesmos valores notícias? Serão as informações consideradas importantes para o Terceiro Setor, importantes também para quem seleciona as notícias e lhes dá espaço e publicidade? Esta ainda é uma questão a ser verificada em pesquisas posteriores.

O que é possível por hora é verificar os discursos que já estão postos - conteúdos manifestos -, tarefa que levaremos adiante nos limitando apenas aos grandes jornais e ao jornal que é objeto de nossa pesquisa. Partimos do pressuposto de que os jornais regionais, não tendo manuais de orientação e conduta, adotam procedimentos oriundos dos principais jornais, irradiadores do que Nelson Traquina apontou como a cultura jornalística.

O projeto editorial que a Folha de São Paulo vem desenvolvendo desde 1970, cristalizado em seu Manual da Redação, é um dos poucos que apresenta com mais clareza quais características deve possuir uma notícia para ser considerada importante:

“1) Ineditismo (a notícia é mais importante do que a já publicada); 2) Improbabilidade (a notícia menos provável é

Comun. Inf., v. 4, n. 1/2, p.73-92, jan./de? ?001 
mais importante do que a esperada); 3) Interesse (quanto mais pessoas possam ter sua vida afetada pela notícia, mais importante ela é); 4) Apelo (quanto maior a curiosidade que a notícia possa despertar, mais importante ela é); 5) Empatia (quanto mais pessoas puderem se identificar com o personagem e a situação da notícia, mais importante ela é); 6) Proximidade (quanto maior a proximidade geográfica entre o fato gerador da notícia e o leitor, mais importante ela é). Ao levar em consideração esses critérios, não se esqueça de que as reportagens da Folha devem atender às necessidades de informação de seus leitores, que formam um grupo particular dentro da sociedade. Esses interesses mudam, e o jornal participa de modo ativo desse processo".

Há nas orientações do Projeto Folha um claro indício da importância que o leitor, o consumidor do produto jornalístico, tem na definição de temas e assuntos, interesse verificado cotidianamente com a introdução da prática de pesquisa de satisfação. "Um dos maiores desafios da Folha daqui em diante será compatibilizar os interesses de um leitor cada vez mais encerrado em seu universo individual com um jornalismo capaz de lançar nova luz sobre um espaço público hoje difícil de identificar", afirma o então editor do Painel Fernando de Barros e Silva, na publicação que marcou a comemoração de 80 anos da Folha.

A mesma prática de identificar a satisfação do leitor diariamente foi introduzida pelo jornal O Popular desde o dia 9 de setembro de 1996. São entrevistados, diariamente, pelo programa Pesquisa de Satisfação do Assinante, em média, 500 assinantes. "Esse flash do momento, além de dar aos editores e repórteres a noção de que os leitores gostaram ou não no jornal, influencia na escolha de novas temas e na tomada de decisões na Redação, mas não altera a linha editorial, definida pela diretoria da empresa", afirmou uma de seus editores-executivos, Cileide Alves, em caderno especial de comemoração de 60 anos do veículo. A editora afirma ainda que:

\footnotetext{
"A redação tem a difícil missão de entender a expectativa do leitor e, ao mesmo tempo, incluir na pauta assuntos que aparentemente não têm a simpatia do leitor mas que são importantes para a sociedade".
}

Abertamente orientado pelo Manual de Redação e Estilo do jornal O Estado de São Paulo, o jornal O Popular carece de maior clareza quanto aos valores notícias que orientam os seus jornalistas no exercí-

Comun. Inf., v. 4, n. 1/2, p.73-92, jan./dez. 2001 
cio diário de selecionar apenas poucas notícias, em meio ao excesso de outras tantas, que disputam diariamente um espaço na arena simbólica do debate público que é o jornal.

\title{
Princípios de um projeto editorial
}

Contudo, um olhar com mais acuidade nas publicações que explicam os princípios que orientam o projeto gráfico dão uma idéia dos valores que estão subjacentes a esse exercício. Vão nessa direção, as explicações que deu seu editor-chefe, Isanulfo Cordeiro, por ocasião do lançamento do novo projeto gráfico, ocorrido em sete de abril de 2002:

\begin{abstract}
"Se é o maior jornal de Goiás é porque tem as características que o bom jornal deve ter: a inquietação, a sadia aflição de informar em primeiro lugar, a notícia transmitida com segurança, a defesa e a promoção de valores sociais, culturais e econômicos da região (esta marca deixada por seus fundadores, os irmãos Câmara), o compromisso único e inafastável com o leitor".
\end{abstract}

A primeira edição de $\mathrm{O}$ Popular chegou às ruas no dia 3 de abril de 1938, com quatro páginas, a 500 réis e circulando duas vezes na semana. A 7 de abril de 2002, portanto, 64 anos depois, O Popular chegou à sua nona mudança de projeto gráfico e editorial.

Um dos sete pontos capitais desse novo projeto gráfico, que, segundo os editores, está sintonizado com as tendências do jornalismo contemporâneo, é a prestação de serviço, traduzida em reportagens com essa característica em todo o corpo do jornal e em uma coluna fixa diária, que trata de assuntos diferentes, tais como: direitos do consumidor, habitação, concursos, etc. Uma outra afirmação de seu editor-chefe indica as preocupações que orientam o jornal:

"O jornal pretende ser mais útil - no sentido de dar ao leitor informação que lhe ajude no seu dia-a-dia - e capacitante garanta ao leitor informações que lhe ajude a agir como cidadão, a torná-lo experto em assuntos importantes". (...) A sobrevivência do meio jornal, depende essencialmente de credibilidade (...), ética, isenção, responsabilidade e estreito compromisso com a comunidade".

Comun. Inf., v. 4, n. 1/2, p.73-92, jan./dez. 2001 
Os editores e os proprietários do jornal comungam a idéia do jornal como espelho da sociedade, concepção que ainda encontra um grande espaço nas redações e em algumas faculdades de Jornalismo do Brasil. Ora expressa pela idéia de uma fotografia da sociedade em sua essência pluralista - como definiu seu ex-editor chefe Agnaldo Alves de Faria - ora comparada com a vida: "Assim é a vida e assim deve ser o jornal - um espelho, em última análise" - na visão do atual editor-chefe Isanulfo Cordeiro e, por fim. como um espelho da comunidade, como o classificou Jaime Câmara Júnior, presidente da Organização Jaime Câmara.

A idéia da notícia como um espelho da realidade defende a "objetividade" como um elemento-chave da atividade jornalística. Dentro dessa concepção, o máximo que se admite é a possibilidade de que as notícias reflitam o ponto de vista do jornalista. Por outro lado, Gaye Tuchman defende que a notícia não espelha a realidade. Para a autora, a notícia ajuda a constituí-la como um fenômeno social compartilhado, uma vez que no processo de definir um acontecimento a notícia define e dá forma a esse acontecimento. Ou seja, a notícia está permanentemente definindo e redefinindo, constituindo e reconstituindo fenômenos sociais.

Ora, como espelho da comunidade e da sociedade nas quais está inserido, fica fácil entender o espaço que $\mathrm{O}$ Popular tem dado ao Terceiro Setor. Mas isso, só, não explica tudo. De que forma o veículo absorve essa influência e o que está por trás de seu interesse em divulgar essas práticas: puro altruísmo? Consciência de seu papel e função social ou mero interesse mercadológico? Qual é a sua pauta espontânea de temas sociais? A julgar somente o conteúdo manifesto, O Popular tem mostrado de fato uma clareza quanto ao seu papel: "Nos últimos anos, os grandes jornais brasileiros ampliaram as discussões sobre o papel e a responsabilidade social que detêm".

Por outro lado, se considerarmos a fina sintonia que vem se construindo entre a redação e o leitor, entenderemos por que o veículo tem dado tanto espaço a matérias veiculadas pelo Terceiro Setor, sobretudo às matérias que envolvem práticas empresariais baseadas na cidadania e no conceito de Responsabilidade Social, matérias que, por uma dedução lógica, atendem aos interesses de seu leitor médio.

O leitor médio de O Popular tem forte referencial familiar. É conservador em questões que envolvem religiosidade e valores culturais. Tem média de idade entre 30 e 45 anos. Preocupa-se com questões

Comun. Inf., v. 4, n. 1/2, p.73-92, jan./dez. 2001 
culturais, políticas e sociais. Segundo pesquisas realizadas pela TMK Telemarketing, 95\% dos leitores afirmam que todos os assuntos importantes merecem destaque nas edições de O Popular. Três por cento disseram que não sabem/não opinam. E os outros $2 \%$ se situam entre aqueles que afirmam que as manchetes são exageradas em relação às matérias internas e que assuntos importantes não receberam destaque.

\section{$O$ agendamento do Terceiro Setor}

Uma série especial de cinco matérias sobre Cidadania Empresarial - ver em anexo-, publicadas na editoria de economia, em dias alternados, entre abril e maio de 2002, no jornal $O$ Popular, configura-se como um caso paradigmático dessa dinâmica de relações entre Terceiro Setor e jornalismo impresso. (Aprendendo a fazer o bem - 28 de abril; Faça a diferença - 5 de maio; Ecologicamente corretas -8 de maio; Valorize seu funcionário - 12 de maio; e Eles agradecem a ajuda -19 de maio).

Ao contrário do que apontam Molotch e Lester, para além do conflito, o que se verifica no caso desse agendamento arquitetado pelo Instituto Ethos é um processo de "cooperação" muito camarada entre promotores e jornalistas, na produção das notícias, contrariando as orientações dos manuais de jornalismo quanto às posturas que se deve ter em relação às fontes da notícia, sobretudo quando possuem um caráter promocional.

O repórter Jarbas Rodrigues Jr., responsável pela série de matérias sobre Cidadania Empresarial, admitiu, em entrevista por e-mail (Cf. em anexo), que vem realizando há dois anos matérias sobre responsabilidade social. Nas primeiras matérias, segundo o jornalista, "o Instituto Ethos teve acesso ao material, e assim iniciaram os primeiros contatos com a entidade". Um outro dado que ajuda também a entender as relações de O Popular com as idéias do Instituto Ethos é o fato de o seu editor-chefe, Isanulfo Cordeiro, integrar a rede de jornalistas da organização.

A idéia de realizar a série de matérias surgiu, segundo Jarbas Rodrigues Jr., no início deste ano. "Tivemos a idéia de realizar uma série de reportagens, no objetivo de disseminar essa nova cultura empresarial". A afirmação, entre aspas, do jornalista de O Popular revela essa cooperação entre o jornal e a entidade, figurando o primeiro como

Comun. Inf., v. 4, n. 1/2, p.73-92, jan./dez. 2001 


\section{6}

um colaborador da ONG, na sua missão de influenciar o empresariado para o compromisso com a responsabilidade social.

É de muita utilidade o conceito de enquadramento, utilizado por Erving Goffman, para análise dessa série de reportagens. Mas um enquadramento antes realizado pelo Terceiro Setor e não pelo jornalismo, como postula a Teoria do Agendamento. Segundo o autor, a análise da construção da notícia implica a utilização de enquadramentos (frames), à forma como organizamos a vida cotidiana, para compreendermos e respondermos às situações sociais.

A análise de conteúdo da série de matérias sobre Cidadania Empresarial, publicada pelo $\mathrm{O}$ Popular, deixa entrever o enquadramento à priori, engendrado pelo Instituto Ethos e reproduzido pelo O Popular. Cada reportagem da série foi estruturada a partir de um dos princípios que compõem o conceito de Responsabilidade Social: desenvolvimento de projetos que beneficiam a comunidade, melhor relacionamento com o meio ambiente e com os consumidores, valorização e respeito aos funcionários, cuidado na escolha de fornecedores e parceiros.

O método de interpretação baseado nos enquadramentos estabelece os princípios de seleção e os códigos de ênfase na elaboração da notícia ou na construção da 'estória'. Dispositivos do enquadramento: as metáforas, os exemplos históricos, as citações curtas, as descrições e as imagens. As matérias produzidas pelo O Popular apresentam um farto repertório desses dispositivos de enquadramento.

Não falta a apresentação de exemplos e casos de empresas e instituições bem sucedidas na aplicação da prática de responsabilidade social, como é o caso, por exemplo, da Usina Jalles Machado S.A., localizada em Goianésia (GO), que garante assistência médica e odontológica para todos os seus 1.800 trabalhadores. Exemplo citado na matéria "Valorize seus funcionários", publicada na página 22, dia 12 de maio de 2002. E também de exemplos como o Guia da Cidadania, publicado na matéria "Eles agradecem sua ajuda", página 18, que ensina os passos, bem ao receituário do Instituto Ethos, de como chegar às principais metas das empresas socialmente responsáveis.

Perguntado se $\mathrm{O}$ Popular vai inscrever a série de reportagens à segunda edição do Prêmio Ethos de Jornalismo, o jornalista arremata:

"Sem dúvida. Aliás, já está inscrita. Como eu publiquei numa das matérias da reportagem especial: não basta apenas fazer, é preciso mostrar que você está fazendo, para que sirva de

Comun. Inf., v. 4, n. 1/2, p.73-92, jan./dez. 2001 
exemplo e reconhecimento. Assim, cria estímulo para que essa ação seja duradoura".

Há por parte de quem produziu a matéria uma clara sintonia com o conceito de Responsabilidade Social, a ponto de analisar o desempenho das empresas, conforme demonstra, abaixo, o trecho da entrevista concedida por Jarbas Rodrigues Jr.:

"Ficamos sabendo que várias empresas em Goiás realizavam algum trabalho social, que embora ainda não possa ser englobado no conceito amplo de responsabilidade social, era o início de uma nova cultura empresarial. A nossa idéia é ampliar essa visão, tanto nas empresas que já fazem algo, como aquelas que pretendem realizar e não sabem como começar".

Contudo, o jornalista afirma que não houve cooperação entre o jornal e o Instituto Ethos na produção da série em questão. "Apenas busquei informações complementares (principalmente para as dicas publicadas nos quadros) no site do Ethos, na internet". Percebe-se, por outro lado, que os princípios que compõem o conceito defendido pelo Ethos estão amplamente difundidos e tipificados nas matérias.

\section{Conclusão}

É inegável o poder que têm exercido os organismos do Terceiro Setor para inscrever suas idéias na Agenda Pública e, portanto, na luta simbólica travada diariamente nas páginas dos jornais. Figurar nesse foro da esfera pública - que são os jornais - é, para o Terceiro Setor, garantia estratégica de sobrevivência no mercado de idéias e na discussão política de questões importantes, segundo as ONGs, para a sociedade.

Nesse jogo de concessões e lobbies muito bem armados, o Terceiro Setor sabe que só com a transformação de um acontecimento ou de uma questão- "issue"- em notícia, seus interesses terão existência pública e serão constituídos em tema de discussão da sociedade. As ONGs, portanto, se inserem nesse jogo político e nessa luta simbólica, com o trabalho de promover ocorrências ao estatuto do acontecimento público, que saltam das suas necessidades de acontecimento.

Como não é detentor do conhecimento especializado produzido pelas organizações do Terceiro Setor e vive sob a ditadura do fator

Comun. Inf., v. 4, n. 1/2, p.73-92, jan./dez. 2001 


\section{8}

tempo na produção da notícia, o jornalismo, em alguns casos, por sua vez, acaba se tornando um refém do enquadramento feito pelas ONGs, que além de influenciarem na escolha da pauta influenciam no tratamento, enfoque e abordagem dos assuntos.

Embora alguns autores descrevam o processo de agendamento como um processo interativo, outros concluíram que a agenda jornalística ficou 'imune' às mudanças da agenda pública. Nesses estudos revisionistas, a clássica síntese de agendamento proposta por Bernard Cohen(1963), segundo a qual os media poderão não nos dizer o que pensar, mas são altamente eficazes em dizer-nos sobre o que pensar - foi virada do avesso. Investigações novas, que exploraram as consequiências do agendamento e do enquadramento feito pelos media, sugerem que os media não só nos dizem sobre o que devemos pensar, como também nos dizem como pensar sobre isso.

Esses estudos afirmam que tanto a seleção das ocorrências e/ou das questões que constituirão a agenda, como a seleção dos enquadramentos para interpretar essas ocorrências e/ou questões são poderes importantes que a Teoria do Agendamento agora identifica depois de mais de vinte anos de vida. A inversão do paradigma está na sua redescoberta do poder do jornalismo.

Contudo, embora ainda seja apenas um estudo de caso, o que não nos credencia a fazer generalizações, é preciso colocar em xeque o "poder do jornalismo", retomando as questões colocadas por Mawell E. McCombs e Donald Shaw: são os próprios media a estabelecer a agenda ou apenas refletem uma agenda estabelecida pelas suas fontes de informação?

O caso colocado em questão - o agendamento do Instituto Ethos para a disseminação do conceito de Responsabilidade Social junto ao empresariado, via mídia impressa - vai mesmo na direção de apontar a existência de uma amigável cooperação entre news promoters e gatekeepers no processo de produção da notícia, com aqueles exercendo, em alguns casos, o poder de determinar o enfoque e o conteúdo das matérias, conforme seus interesses.

Onde, portanto, residiria o poder do jornalismo, tão aclamado pela Teoria do Agendamento? Em tese, reside na autonomia em fixar a sua própria agenda de temas e enfoques e também no poder de selecionar o que entra e o que não entra na disputa simbólica. A questão é que, em alguns casos, como demonstrou essa série de reportagens, antes de dizer à população sobre o que é que deve pensar e também como

Comun. Inf., v. 4, n. 1/2, p.73-92, jan./dez. 2001 
pensar sobre isso, é a sociedade, organizada no Terceiro Setor, com o consentimento do jornalismo, que vai dizer o que ele vai veicular em suas páginas e com quais enfoques e enquadramentos.

\section{Abstract:}

To understand News Promoters's paper in the social construction of the news, with relevance to the sources as one of the key factors in Agenda Setting definition, starting from the relationship of organisms of the Third Section with the journalism printed is the central objective of this work. In the light of the framing concept, used by Erving Goffman,

the author analyzed a special series of five reports on the theme Social Responsibility of the Companies published in the newspaper O Popular, larger newspaper of circulation in Goiás, in alternate days of April to May of 2002. The analysis of content of the reports on Business Citizenship evidenced the framing wise the engendered by the Instituto Ethos and reproduced by the O Popular. The case study concluded that it is necessary to put back in check the power of the journalism, so acclaimed by the Theory of Agendamento, retaking the subjects put by Mawell E. MacCombs and Donald Shaw, pioneers in the agendamento studies: "are the own ones measured to establish the calendar or do theses just reflect an established calendar for their sources of information?"

Kewwords: journalism, social responsability, agenda setting.

\section{Notas}

1. Artigo publicado na segunda parte do livro O Poder do Jornalismo, Análise e Textos da Teoria do Agendamento -Traquina, Nelson. Editora Minerva Coimbra, 2000

2. Conceito apresentado por Luiz Carlos Merege, Coordenador do Centro de Estudos do Terceiro Setor - in Caderno Especial Folha Trainee - Folha de São Paulo, 18 de setembro de 1999.

3. OLIVEIRA SILVA, Jacqueline. Serviços Sociais e $3^{\circ}$ Setor - Notas para discussão. Artigo apresentado no Seminário Sociedade Civil e Política - Desafios na Construção da Democracia, realizado pelo Centro Cultural de Brasília, em maio de 2000.

4. Jornalista, mestre em comunicação e doutor em Sociologia, é professor de sociologia na Faculdade de Comunicação da Universidade de Brasília, onde coordena o projeto de pesquisa SOS-Imprensa ("Formas de Apoio aos Usuários da Imprensa - CNPq/PIBIC) e o programa de pós-graduação.

5. Artigo publicado na segunda parte do livro O Jornal da Forma ao Sentido, organizado por Sérgio Dayrell Porto e Maurice Mouillaud, publicado pela Paralelo 15, 1997.

Comun. Inf., v. 4, n. 1/2, p.73-92, jan./dez. 2001 
6. Lúcia Avelar: doutora em ciência política, com pós-graduação em Yale University/EUA, ex-professora da Unicamp, é professora do Departamento de Ciência Política da Universidade de Brasília.

7. Cf. em artigo publicado na primeira parte do livro Jornalismo: Questões, Teorias e "Estórias", organizado por Nelson Traquina, publicado pela coleção Comunicação \& Linguagens, Editora Veja, 1993.

\section{Referências}

AVELAR, Lúcia. Elites Políticas, o Eleitorado Brasileiro e Perspectivas da Democracia na Década Vindoura. Comunicação oral apresentada no seminário "Perspectivas da Democracia no Século XXI", Teresópolis, jun. 1998.

BERGER L. Peter.; LUCKMANN, Thomas. A Construção Social da Realidade. Petrópolis: Vozes, 1985.

BARROS FILHO, Clóvis de.; BARTALOZZI, Pedro Lozano. (Colab.). Ética na Comunicação: da informação ao receptor. São Paulo: Moderna, 1995.

POR QUE mudar? 7 pontos capitais. O Popular. Goiânia, 7 abr. 2002. Caderno especial.

FOLHA DE SÃO PAULO, São Paulo, 18 fev. 2001. Caderno especial 21.

GENRO FILHO, Adelmo. O Segredo da Pirâmide: para uma teoria marxista do jornalismo. Revista da Fenaj, Brasília, v. 1, n. 1. maio 1996.

GRAU, Nuria Cunill. Repensando o público através da sociedade. Rio de Janeiro: ENAP, 1998.

MANUAL de Redação. 3. ed. São Paulo: Publifolha, 2001.

MARCONDES FILHO, Ciro. O Capital da Notícia: jornalismo como produção social da segunda natureza. São Paulo: Ática, 1989.

WILLETTS, P. (Ed.). The consciense of the world. The influence of NonGovernmental Organizations in the UN System. Londres: Hurst and Washington, Brooking Institution, 2001.

SILVA, Jacqueline Oliveira. Serviços Sociais e Terceiro Setor: notas para discussão. Comunicação oral apresentada no Seminário Sociedade Civil e Política: desafios na construção da democracia. Brasília, maio 2000.

SILVA, Carlos E. Lins da. O Adiantado da Hora: a influência americana sobre o jornalismo brasileiro. São Paulo: Summus, 1991.

60 ANOS de história. O Popular. Goiânia, 3 abr. 1998. Suplemento especial.

TRAQUINA, Nelson. (Org.). O Poder do Jornalismo: análise e textos da teoria do agendamento. Coimbra: Minerva, 2000.

. Jornalismo: Questões, Teorias e "Estórias". Lisboa: Ed. Veja,

1993.

THOMPSON, John B. Ideologia e Cultura Moderna: teoria social crítitca na era dos Meios de Comunicação de Massa. Petrópolis: Vozes, 1995.

TUCHMAN, Gaye. La producion de la noticia: estudio sobre la construción de la realidade. Barcelona: Bosch, 1993.

Comun. Inf., v. 4, n. 1/2, p.73-92, jan./dez. 2001 


\section{Anexo 1}

\section{Questões encaminhadas ao editor de economia de O Popular:}

1 - Quando e em que situações se deu o contato do Jornal O Popular com as idéias e os conceitos promovidos pelos Instituto Ethos de Empresas e Responsabilidade Social? Foi algo espontâneo? Partiu de O Popular ou do próprio Instituto Ethos?

2 - De abril a maio, O Popular publicou uma série de cinco reportagens sobre Empresas Cidadãs, cujo mote central foram os indicadores estabelecidos pelo Ethos (meio-ambiente, fornecedores, trabalhadores, comunidade...) de responsabilidade social. De onde surgiu a idéia de fazer esta série de matérias?

3 - Houve, durante a produção das matérias, um contato mais formal $\mathrm{O}$ Popular/Ethos para obtenção de informações? Se houve, como o Instituto Ethos se comportou?

4 - Quais os objetivos do jornal O Popular com a publicação desta série sobre Empresas Cidadãs?

5 - O jornal O Popular vai inscrever esta série de matérias à próxima edição do Prêmio Ethos de Jornalismo?

Estamos checando algumas destas informações tb junto ao próprio Instituto Ethos. O jornal Correio Braziliense, de Brasília, também é objeto desta pesquisa. A resposta a estas perguntas muito enriquecerá nossa pesquisa.

\section{Anexo 2}

\section{Respostas do jornal O Popular:}

1 - Como repórter, venho realizando há dois anos matérias sobre responsabilidade social. Mas de forma esporádica. No início deste ano, tivemos a idéia de realizar uma série de reportagens, no objetivo de disseminar essa nova cultura empresarial. Nas primeiras matérias, o Instituto Ethos teve acesso ao material, e assim iniciaram os primeiros contatos com a entidade. Além disso, o editor-chefe do nosso jornal, Isanulfo Cordeiro, faz parte de uma rede de jornalistas do Instituto Ethos.

2 - Como disse anteriormente, o objetivo nosso é disseminar a cultura da responsabilidade social. Ficamos sabendo que várias empresas em Goiás realizavam algum trabalho social, que embora ainda não possa ser englobado no conceito amplo de responsabilidade social, era o início de uma nova cultura empresarial. A nossa idéia é ampliar essa visão, tanto nas empresas que já fazem algo, como aquelas que pretendem realizar e não sabem como começar.

Comun. Inf., v. 4, n. 1/2, p.73-92, jan./dez. 2001 
3 - De minha parte, não. Apenas busquei informações complementares (principalmente para as dicas publicadas nos quadros) no site do Ethos, na internet.

4 - Acredito que essa resposta já está explícita nas anteriores.

5 - Sem dúvida. Aliás, já está inscrita. Como eu publiquei numa das matérias da reportagem especial: não basta apenas fazer, é preciso mostrar que você está fazendo, para que sirva de exemplo e reconhecimento. Assim, cria estímulo para que essa ação seja duradoura.

\section{Anexo 3}

\section{Questões encaminhadas ao Instituto Ethos:}

1 - O Jornal O Popular, em Goiás, publicou, de março a maio, uma série de cinco reportagens especiais sobre terceiro setor. Em cada uma das matérias, abordou um dos indicadores de responsabilidade social.

Gostaria de saber:

a) Houve algum contato formal do Instituto Ethos sugerindo a O Popular a produção dessas matérias?

b) Houve algum contato formal de O Popular com o Instituto Ethos pedindo auxilio para pensar as matérias?

2 - Quais estratégias usadas pelo Instituto Ethos para agendar a mídia, sobretudo a mídia impressa?

3 - Quando é que um jornal, em sua linha editorial e matérias, pratica a responsabilidade social?

Comun. Inf., v. 4, n. 1/2, p.73-92, jan./dez. 2001 